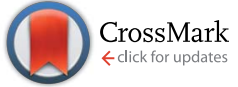

Cite this: RSC Adv., 2015, 5, 12597

Received 8th December 2014 Accepted 13th January 2015

DOI: 10.1039/c4ra15953e

www.rsc.org/advances

\title{
Controlled ionic conductivity via tapered block polymer electrolytes $\uparrow$
}

\author{
Wei-Fan Kuan, ${ }^{a}$ Roddel Remy, ${ }^{b}$ Michael E. Mackay ${ }^{\text {ab }}$ and Thomas H. Epps, III ${ }^{\star a b}$
}

We present the design of novel solid electrolytes using tapered block polymers (TBPs). In this work, we synthesize a series of TBPs via atom transfer radical polymerization (ATRP) consisting of rigid polystyrene and ion-conducting poly(oligo-oxyethylene methacrylate) segments and explore the role of tapered interfaces on ion transport. Previous studies on TBPs have shown that manipulating the taper composition in block polymers can reduce the unfavorable polymer-polymer interactions between blocks, enabling the design for highly-processable (lower order-disorder transition temperature) polymer electrolytes. Herein, we demonstrate that the taper profile and taper volume fraction significantly impact the glass transition temperatures $\left(T_{\mathrm{g}} \mathrm{s}\right)$ in block polymer electrolytes, thus affecting the ionic conductivity. Additionally, we find that the normal-tapered materials with $\approx 60$ vol\% tapering exhibit remarkable improvements in ionic conductivity (increase $\approx 190 \%$ at $20{ }^{\circ} \mathrm{C}$ and increase $\approx 90 \%$ at $80{ }^{\circ} \mathrm{C}$ ) in comparison to their non-tapered counterparts. Overall, our TBPs, with controllable interfacial interactions, present an exciting opportunity for the fabrication of cost-effective, highly-efficient, and stable energy storage membranes.

\section{Introduction}

Rechargeable lithium-metal batteries are among the most promising technologies for future electrochemical energy storage devices due to their high energy densities, low selfdischarge rates, and minimal memory effects. ${ }^{1-6}$ However, conventional liquid electrolytes in lithium-metal batteries are potential hazards due to dendrite formation that can shortcircuit batteries during repeated charge-discharge cycles. ${ }^{7-9}$ Moreover, recent incidents with commercial lithium ion battery packs in the transportation industry indicate that the flammable organic liquid electrolyte may allow batteries to become thermally and electrochemically unstable. ${ }^{10}$ These safety and performance concerns have promoted interest in solid-state lithium-metal batteries containing solvent-free electrolytes. ${ }^{11-13}$

Block polymers (BPs) have been investigated extensively as solid-state electrolytes for rechargeable lithium-metal batteries due to their ability to self-assemble into ordered nanostructures. ${ }^{14-16}$ Such BP nanostructure formation, governed by the segregation strength $(\chi N, \chi$ : Flory-Huggins interaction

${ }^{a}$ Department of Chemical and Biomolecular Engineering, University of Delaware, Newark, DE 19716, USA. E-mail: thepps@udel.edu

${ }^{b}$ Department of Materials Science and Engineering, University of Delaware, Newark, DE 19716, USA

$\dagger$ Electronic supplementary information (ESI) available: Plot of the reactivity ratio evaluation of styrene and OEM monomers, plot of the taper composition profile as a function of ATRP reaction time, and additional characterization data (GPC, SAXS, and DSC). See DOI: 10.1039/c4ra15953e parameter and $N$ : degree of polymerization) and volume fraction $(f)$ of the block, permits simultaneous control over ion transport and mechanical strength, thus providing an enticing opportunity toward fabricating designer materials for polymer electrolytes. ${ }^{16-20}$ For example, in diblock copolymer systems, the ion-conducting block can be complexed with lithium salts, and the lithium ion in polymer-salt complexes can be transported via segmental motion of polymer chains. In this case, the nonconducting block can provide mechanical support and suppress dendrite formation. Researchers have reported the preparation of solid-state electrolytes with a combination of high mechanical strength and ionic conductivity using nanostructured BPs. ${ }^{17,21-23}$ For example, Balsara and co-workers designed a highmolecular-weight poly(styrene- $b$-ethylene oxide) (P(S-EO)) BP electrolyte that achieved ionic conductivities on the order of $10^{-4} \mathrm{~S} \mathrm{~cm}^{-1}$ and shear moduli on the order of $10^{8} \mathrm{~Pa}$ at $90^{\circ} \mathrm{C} .{ }^{21}$ Additionally, recent work by Lodge and co-workers demonstrated the preparation of a bicontinuous polymer electrolyte containing interpenetrating domains of cross-linked PS and $\mathrm{PEO} /$ ionic liquid. ${ }^{22}$ Their materials achieved ionic conductivities above $10^{-3} \mathrm{~S} \mathrm{~cm}^{-1}$ and tensile moduli $\approx 10^{8} \mathrm{~Pa}$ at room temperature..$^{22}$ Although these high-molecular-weight polymer electrolytes provide exceptional transport and mechanical properties, the high processing cost due to the high segregation strength, among other factors, has restricted their potential in battery applications. ${ }^{24}$

To overcome the above limitation, we report a new design of BP electrolytes using tapered block polymers (TBPs). TBPs consist of a transition region with a gradient composition 
(a)

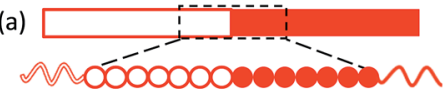

(b)

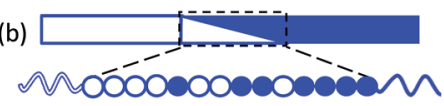

(c)

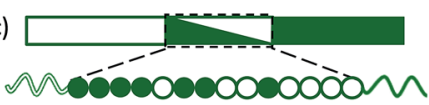

(d)

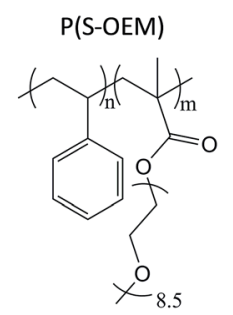

Fig. 1 Illustration of a (a) block polymer, (b) normal-tapered block polymer, and (c) inverse-tapered block polymer. (d) Molecular structure of $\mathrm{P}(\mathrm{S}-\mathrm{OEM})$.

profile between two pure blocks as shown in Fig. $1 .^{25-29}$ This architecture differs from gradient copolymers, which have a graded compositional profile extending along the entire polymer chain. ${ }^{30-35}$ Previous studies have demonstrated that manipulating the segment distribution in BP systems can decrease the effective segregation strength between blocks by reducing the effective $\chi$; in other words, the processing temperatures can be tuned independent of the chemical constituents and the molecular weight (i.e., mechanical properties) using tapered interfaces. ${ }^{26,32,35-38}$ Additionally, the intermixing between two polymer domains in BPs substantially increases block compatibility, enabling independent control over BP chain stretching and the glass transition temperature $\left(T_{\mathrm{g}}\right)$ at a constant chemical composition. ${ }^{28,29,31,39-42}$ Moreover, both experimental and theoretical work on TBPs has shown that these materials are able to selfassemble into ordered cylinder and complex network nanostructures, which are advantageous for polymer electrolytes due to their three-dimensional conducting pathways. ${ }^{25,26,37}$ These unique properties make TBPs attractive candidates for potential conducting applications.

In this work we applied, for the first time, TBPs as electrolytes and explored the role of tapered interfaces on the ionic conductivity using a model system comprised of mechanically rigid PS and ion-conducting poly(oligo-oxyethylene methacrylate) (POEM) (Fig. 1(d)). POEM was chosen in this work for its superior room temperature conductivity relative to PEO as a result of a significantly reduced driving force toward crystallization in POEM..$^{\mathbf{2 4 3 3 , 4 4}}$ The influence of tapering on ionic conductivity was studied relative to taper profile (normaltapered $v s$. inverse-tapered) and taper volume fraction. By developing a better understanding of TBPs, this work provides a promising strategy for designing novel polymer electrolytes with a combination of improved ionic conductivity and sufficient mechanical strength, without compromising processability.

\section{Experimental}

\section{Materials}

Styrene monomers (99\%, stabilized, Acros Organics) and oligooxyethylene methacrylate monomers (OEM, >99\%, stabilized, Sigma-Aldrich, average molar mass $=475 \mathrm{~g} \mathrm{~mol}^{-1}$ ) were purified by passage through basic alumina columns. The styrene monomer also was dried by distilling from calcium hydride. Both monomers were degassed by three freeze-pump-thaw cycles before use. Propargyl 2-bromoisobutyrate (PgBiB) was synthesized according to literature procedures (yield $\approx 80$ wt\%). ${ }^{45}$ Copper bromide $(\mathrm{Cu}(\mathrm{I}) \mathrm{Br}, 98 \%$, Acros Organics) was purified by stirring in acetic acid for $20 \mathrm{~min}$, filtering, washing twice with cold ethanol, and drying under dynamic vacuum. $N, N, N^{\prime}, N^{\prime \prime}, N^{\prime \prime \prime}$-pentamethyldiethylenetriamine (PMDETA, 99\%, Sigma-Aldrich), tetrahydrofuran (THF, >99\%, optima, Fisher Scientific), and anisole ( $>99 \%$, Fisher Scientific) were degassed before storing in an argon-filled glove box. Lithium trifluoromethanesulfonate (lithium triflate, $\mathrm{LiCF}_{3} \mathrm{SO}_{3}, 99 \%$, Sigma-Aldrich) was dried at room temperature under dynamic vacuum overnight before being transferred into the glove box.

\section{Synthesis of tapered block polymers (TBPs)}

The synthesis of TBPs was accomplished via atom transfer radical polymerization (ATRP). The PS block was polymerized at $100{ }^{\circ} \mathrm{C}$ in a mixture of $\mathrm{Cu}(\mathrm{I}) \mathrm{Br}(0.73 \mathrm{mmol})$, PMDETA (1.46 mmol), styrene (0.3 mol), and anisole $(17 \mathrm{ml})$ using PgBiB $(0.73 \mathrm{mmol})$ as the initiator. The reaction proceeded for $8 \mathrm{~h}$ and was terminated by cooling at room temperature and exposing to air. The Br-capped PS (PS-Br) was purified by passage through a neutral alumina column and followed by precipitation from methanol. The number-average molar mass $\left(M_{\mathrm{n}}\right)$ and dispersity $(\nexists)$ were determined using gel permeation chromatography (GPC) on a Viscotek 270Max instrument fitted with Waters Styragel HR1 and HR4 columns in series, operating with THF as the mobile phase, and calibrated using PS standards. PS-Br served as the macroinitiator for the semi-batch synthesis of the normal-tapered and inverse-tapered polymers. Styrene and OEM monomers were added to the reactor vessel at predetermined flow rates using automated syringe pumps. The flow rates were calculated based on monomer reactivity ratios determined from the Mayo-Lewis relationship (ESI Fig. S1†). ${ }^{\mathbf{4 6}}$ To confirm the composition profile in the taper, aliquots were taken during the polymerization of the tapered segment and analyzed via proton nuclear magnetic resonance $\left({ }^{1} \mathrm{H}\right.$ NMR) spectroscopy (Bruker AV-400) (ESI Fig. S2 $\dagger$ ). The ATRP reaction to form the tapered segment was designed to reach the desired composition and molecular mass at relatively low monomer conversions $(\approx 30 \%)$ to maximize the bromine endgroup fidelity. At the end of the taper region polymerization, pure OEM monomer was added to the reactor for the synthesis of the POEM block. The final TBP was purified by passage through neutral alumina and precipitation from cold isopropanol. The non-tapered P(S-OEM) BP was synthesized in a similar fashion but with no tapering step. $M_{\mathrm{n}}, D$, and POEM volume fraction were characterized via a combination of GPC and ${ }^{1} \mathrm{H}$ NMR using 
Table 1 Molecular characterization of block polymers

\begin{tabular}{|c|c|c|c|c|}
\hline Polymer & $f_{\text {taper }}{ }^{a}$ & $M_{\mathrm{n}}\left(\mathrm{kg} \mathrm{mol}^{-1}\right)$ & 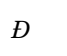 & $f_{\mathrm{PS}}^{b}$ \\
\hline $\mathrm{P}(\mathrm{S}-\mathrm{OEM})$ & 0 & 35.0 & 1.17 & \\
\hline $\mathrm{P}(\mathrm{S}-\mathrm{SOEM}-\mathrm{OEM})_{0.62}$ & 0.62 & 33.0 & 1.13 & 0. \\
\hline $\mathrm{P}(\mathrm{S}-\mathrm{SOEM}-\mathrm{OEM})_{0.32}$ & 0.32 & 31.0 & 1.10 & 0.5 \\
\hline $\mathrm{P}(\mathrm{S}-\mathrm{OEMS}-\mathrm{OEM})_{0.61}$ & 0.61 & 32.0 & 1.17 & 0.4 \\
\hline $\mathrm{P}(\mathrm{S}-\mathrm{EO})$ & 0 & 53.1 & 1.09 & 0.2 \\
\hline
\end{tabular}

${ }^{a}$ Taper volume fraction in BPs. ${ }^{b}$ Overall PS volume fraction $\left(f_{\mathrm{PS}}=1-\right.$ $f_{\mathrm{POEM}}$ and $\left.f_{\mathrm{PS}}=1-f_{\mathrm{PEO}}\right)$.

homopolymer densities at room temperature $\left(\rho_{\mathrm{PS}}=1.05 \mathrm{~g}\right.$ $\mathrm{cm}^{-3},{ }^{47} \rho_{\text {POEM }}=1.22 \mathrm{~g} \mathrm{~cm}^{-3}$ ), for which the density of POEM was estimated using group contribution theory. ${ }^{48}{ }^{1} \mathrm{H}$ NMR $\delta_{\mathrm{H}}$ (400 MHz; $\mathrm{CDCl}_{3} ; \mathrm{Me}_{4} \mathrm{Si}$ ) 7.2-6.3 (5H, br m, Ar-H), 4.2 (2H, br s, $\mathrm{CH}_{2}$, OEM side chain), 3.9-3.5 (br m, $\mathrm{CH}_{2}$, OEM side chain), 3.4 (3H, s, $\mathrm{CH}_{3}$, OEM side chain), 2.2-0.7 (br m, CH, $\mathrm{CH}_{2}, \mathrm{CH}_{3}$, polymer backbone). The characterization results for all samples are listed in Table 1. Normal-tapered and inverse-tapered samples are denoted as $\mathrm{P}(\mathrm{S}-\mathrm{SOEM}-\mathrm{OEM})_{x}$ and $\mathrm{P}(\mathrm{S}-\mathrm{OEMS}$ $\mathrm{OEM})_{x}$, respectively, for which $x$ represents the taper volume fraction in the TBP.

\section{Preparation of salt-doped samples}

Salt-doped polymers were prepared in an argon-filled glove box to prevent moisture uptake. Polymers were dried rigorously before transferred into the glove box. Measured amounts of polymers and $\mathrm{LiCF}_{3} \mathrm{SO}_{3}$ were dissolved in anhydrous THF, followed by solvent removal under dynamic vacuum, and then stored in the glove box.

\section{Small-angle X-ray scattering (SAXS)}

Synchrotron SAXS experiments were conducted on the DNDCAT 5-ID-D beamline at the Advanced Photon Source of Argonne National Laboratory with an incident beam of wavelength $\lambda=0.7293 \AA$ and a Mar CCD detector at a sample-todetector distance of $8503 \mathrm{~mm}$ (APS-SAXS). Lab source SAXS experiments were conducted at the University of Delaware (UD) on a Rigaku SAXS instrument as described elsewhere (UDSAXS) ${ }^{49}$ All two-dimensional scattering data were azimuthally integrated, resulting in plots of scattered intensity versus scattering vector, $q=4 \pi \lambda^{-1} \sin (\theta / 2)$, for which $\theta$ is the scattering angle. All SAXS samples were pre-annealed at $120^{\circ} \mathrm{C}$ for $2 \mathrm{~h}$, heated to $150{ }^{\circ} \mathrm{C}$ for $2 \mathrm{~h}$, and then cooled to $30{ }^{\circ} \mathrm{C}$ under dynamic vacuum. APS-SAXS and UD-SAXS data were acquired at $30{ }^{\circ} \mathrm{C}, 120{ }^{\circ} \mathrm{C}$, and $150{ }^{\circ} \mathrm{C}$ heating ramp with $15 \mathrm{~min}$ annealing at each temperature. APS-SAXS experiments were performed under nitrogen flow, and UD-SAXS experiments were conducted under dynamic vacuum.

\section{Transmission electron microscopy (TEM)}

BP morphologies were examined on a JEM-3010 TEM. TEM samples were prepared following the same pre-annealing protocol used for the SAXS specimens. Samples were cut into $\approx 70 \mathrm{~nm}$ slices at $-120{ }^{\circ} \mathrm{C}$ using a cryo Leica Reichart Ultracut $\mathrm{S}$ microtome. The TEM was operated at an accelerating voltage of $200 \mathrm{kV}$. The POEM domain was stained with ruthenium tetroxide $\left(\mathrm{RuO}_{4}\right)$ vapor at room temperature for $\approx 60 \mathrm{~s}$ to enhance contrast prior to imaging.

\section{AC impedance spectroscopy}

A Princeton Applied Research PARSTAT 2273 frequency response analyzer with a homemade test cell on a Linkam HFS91 CAP stage was used to conduct ionic conductivity measurements. Polymer specimens were hot-pressed into disks under vacuum in the glove box and then placed into a test cell as described previously. ${ }^{50}$ Samples were pre-annealed at $120{ }^{\circ} \mathrm{C}$ for $2 \mathrm{~h}$ and then cooled to $20^{\circ} \mathrm{C}$ at $30^{\circ} \mathrm{C} \mathrm{min}{ }^{-1}$ and held for $1 \mathrm{~h}$. The impedance measurements were conducted under dynamic vacuum, and the ionic conductivity was measured on heating. Two impedance measurements were taken at each temperature with $5 \mathrm{~min}$ and $8 \mathrm{~min}$ annealing times. The first measurement is reported in the text, while the second measurement was used to ensure that the ionic conductivity results were consistent during the annealing. The AC frequency range and voltage amplitude were $0.1-1 \mathrm{MHz}$ and $10 \mathrm{mV}$, respectively. The bulk resistance of the electrolyte, $R$, was determined from the highfrequency plateau in the real impedance data, and the ionic conductivity, $\sigma$, was calculated using $\sigma=L /(R A)$, for which $L$ is the sample thickness, and $A$ is the contact area between the sample and the aluminum foil electrode.

\section{Differential scanning calorimetry (DSC)}

DSC experiments were conducted using a TA Instruments Discovery DSC equipped with an RCS90 cooling accessory. Samples were sealed in aluminum pans and heated through three cooling/heating cycles between $-85^{\circ} \mathrm{C}$ and $150{ }^{\circ} \mathrm{C}$ at $10{ }^{\circ} \mathrm{C}$ $\min ^{-1}$ under a nitrogen atmosphere. Baseline calibration was performed with sapphire disks, while the temperature and the cell constant were calibrated using an indium standard. The $T_{\mathrm{g}}$ value was determined from the midpoint of the inflection in the third heating trace.

\section{Results and discussion}

The macromolecular characterization of non-tapered P(S-OEM), normal-tapered $\mathrm{P}(\mathrm{S} \text {-SOEM-OEM })_{0.62}$, and inverse-tapered $\mathrm{P}(\mathrm{S}$ OEMS-OEM $)_{0.61}$ BPs is reported in Table 1. GPC traces, as shown in ESI Fig. S3, $\dagger$ were used to confirm the shifts in molecular mass distributions, indicating the formation of well-defined polymers at each synthetic step. The morphologies of neat (non-doped) and $\mathrm{LiCF}_{3} \mathrm{SO}_{3}$-doped polymers were examined using a combination of SAXS and TEM. SAXS data, acquired at $30{ }^{\circ} \mathrm{C}$, for $\mathrm{P}(\mathrm{S}-$ OEM), $\mathrm{P}(\mathrm{S}-\mathrm{SOEM}-\mathrm{OEM})_{0.62}$, and $\mathrm{P}(\mathrm{S}-\mathrm{OEMS}-\mathrm{OEM})_{0.61}$ are presented in Fig. 2. The neat P(S-OEM) BP (Fig. 2(a)) exhibited SAXS diffraction peaks at $q / q^{*}=1$ and 2 (for which $q^{*}$ was the primary peak location), and the domain spacing of $25.8 \mathrm{~nm}$ in P(S-OEM) was obtained from $q^{*}\left(d=2 \pi / q^{*}\right)$. The peak ratios were indicative of a lamellae (LAM) phase, and the TEM micrograph (Fig. 3(a)) further confirmed the LAM assignment. The domain spacing of 


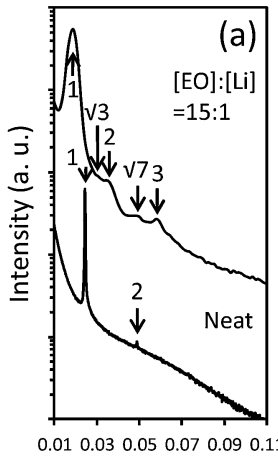
$q\left(\AA^{-1}\right)$

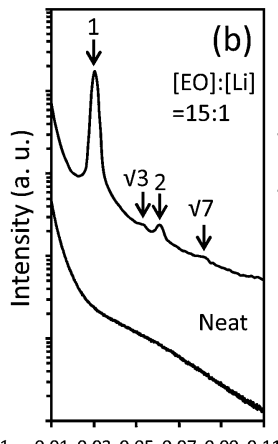

$q\left(\AA^{-1}\right)$

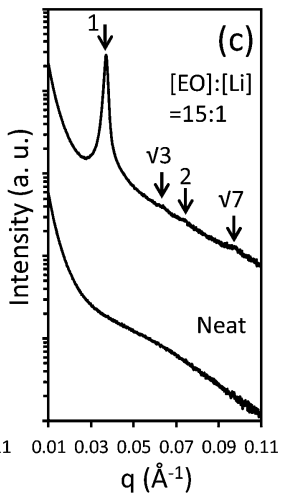

Fig. 2 APS-SAXS data for neat and $\mathrm{LiCF}_{3} \mathrm{SO}_{3}$-doped (a) P(S-OEM), (b) $\mathrm{P}(\mathrm{S}-\mathrm{SOEM}-\mathrm{OEM})_{0.62}$, and (c) P(S-OEMS-OEM) 0.61 . Data were shifted vertically for clarity.
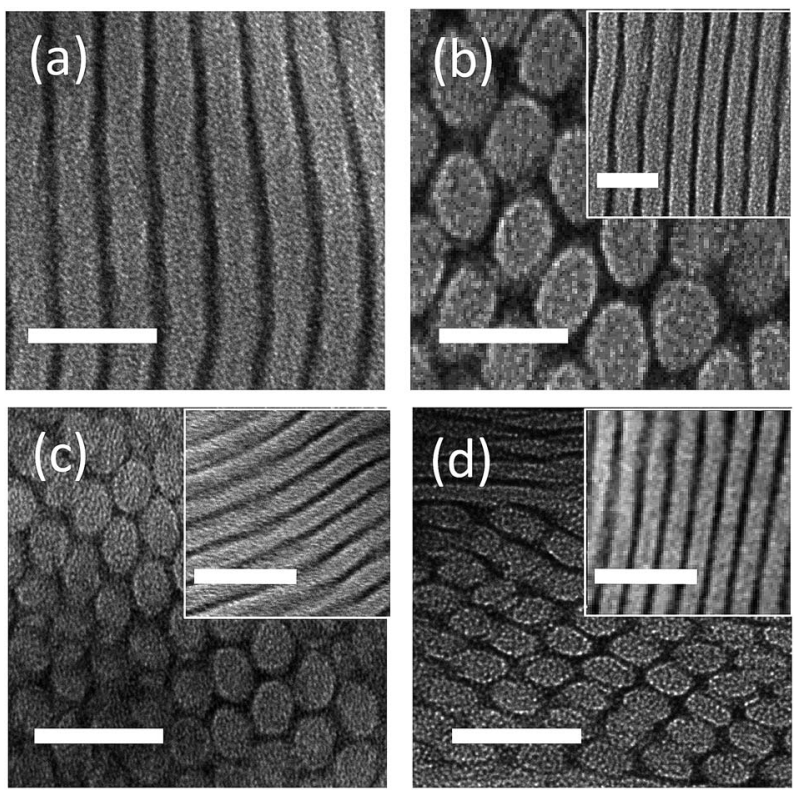

Fig. 3 TEM micrographs of (a) neat P(S-OEM), (b) $\mathrm{LiCF}_{3} \mathrm{SO}_{3}$-doped $\mathrm{P}(\mathrm{S}-\mathrm{OEM})$, (c) $\mathrm{LiCF}_{3} \mathrm{SO}_{3}$-doped P(S-SOEM-OEM) $)_{0.62}$, and (d) $\mathrm{LiCF}_{3}-$ $\mathrm{SO}_{3}$-doped $\mathrm{P}(\mathrm{S} \text {-OEMS-OEM) })_{0.61}$. The $\mathrm{LiCF}_{3} \mathrm{SO}_{3}$-doping ratio was [EO] : [Li] $=15: 1$. TEM samples were stained with $\mathrm{RuO}_{4}$ vapor to darken the POEM domains. Scale bars represent $50 \mathrm{~nm}$.

$\mathrm{P}$ (S-OEM) obtained from TEM was $21.3 \mathrm{~nm}$, which is smaller than that obtained from SAXS. However, the thickness of a PS stripe in Fig. 3(a) was $\approx 13 \mathrm{~nm}$ as expected based on the PS volume fraction and the domain spacing from SAXS. The deviation between SAXS and TEM results likely was due to POEM shrinkage under exposure to the electron beam in TEM. ${ }^{16,50}$ With the addition of $\mathrm{LiCF}_{3} \mathrm{SO}_{3}$ at the salt-doping ratio of [EO]:[Li] $=15: 1$, the primary peak of $\mathrm{P}(\mathrm{S}-\mathrm{OEM})$ shifted to $q^{*}=0.018 \AA^{-1}$, giving a domain spacing of $34.4 \mathrm{~nm}$. The scattering peaks located at $q / q^{*}$ $=1, \sqrt{ } 3,2, \sqrt{ } 7$, and 3 suggest a hexagonally-packed cylinder (HEX) morphology. TEM micrographs showed both hexagonally-packed dots (Fig. 3(b)) and parallel stripes (Fig. 3(b) inset), which support the HEX assignment.
A similar morphological analysis was conducted for normaltapered $\mathrm{P}(\mathrm{S} \text {-SOEM-OEM })_{0.62}$ and inverse-tapered P(S-OEMSOEM $)_{0.61}$ to investigate the effects of taper profile on BP selfassembly. The SAXS patterns for neat $\mathrm{P}(\mathrm{S}-\mathrm{SOEM}-\mathrm{OEM})_{0.62}$ (Fig. 2(b)) and P(S-OEMS-OEM) $)_{0.61}$ (Fig. 2(c)) were featureless and indicative of disordered morphologies. This difference in morphology in comparison to the $\mathrm{P}(\mathrm{S}-\mathrm{OEM})$ specimen was due to the interfacial modification of our tapered polymers and suggested a lower order-disorder transition temperature $\left(T_{\mathrm{ODT}}\right)$ in the tapered materials relative to their non-tapered counterpart. Upon salt doping at $[\mathrm{EO}]:[\mathrm{Li}]=15: 1$, SAXS profiles of $\mathrm{LiCF}_{3} \mathrm{SO}_{3}$-doped P(S-SOEM-OEM) $)_{0.62}$ (Fig. 2(b)) and $\mathrm{LiCF}_{3} \mathrm{SO}_{3^{-}}$ doped P(S-OEMS-OEM) $)_{0.61}$ (Fig. 2(c)) exhibited scattering peaks at $q / q^{*}=1, \sqrt{ } 3,2$, and $\sqrt{ } 7$, indicative of HEX morphologies. The TEM micrographs for $\mathrm{LiCF}_{3} \mathrm{SO}_{3}$-doped $\mathrm{P}(\mathrm{S} \text {-SOEM-OEM })_{0.62}$ (Fig. 3(c)) and $\mathrm{LiCF}_{3} \mathrm{SO}_{3}$-doped P(S-OEMS-OEM) $)_{0.61}$ (Fig. 3(d)) with hexagonally-packed dots and parallel stripes (insets in Fig. 3(c) and (d)) support our HEX assignments. Notably, the domain spacings of $\mathrm{LiCF}_{3} \mathrm{SO}_{3}$-doped $\mathrm{P}(\mathrm{S} \text {-SOEM-OEM })_{0.62}$ and $\mathrm{LiCF}_{3} \mathrm{SO}_{3}$-doped P(S-OEMS-OEM) $)_{0.61}$ were $20.6 \mathrm{~nm}$ and $17.0 \mathrm{~nm}$, respectively, showing a significant deviation from the corresponding non-tapered $\mathrm{LiCF}_{3} \mathrm{SO}_{3}$-doped $\mathrm{P}(\mathrm{S}$-OEM $)\left(d_{\mathrm{P}(\mathrm{S} \text {-OEM):Li }}=\right.$ $34.4 \mathrm{~nm}$ ), especially for the inverse-tapered material. The reduction in $d$ for TBPs was consistent with theoretical predictions by Hall and co-workers. ${ }^{37}$ This result demonstrates that the domain sizes of lithium-doped BPs can be manipulated independent of the chemical constituents and the polymer molecular mass using tapered interfaces.

To determine the effects of tapering on the ionic conductivity, AC impedance experiments were conducted on the HEXforming $\mathrm{P}(\mathrm{S}$-OEM $), \quad \mathrm{P}(\mathrm{S} \text {-SOEM-OEM })_{0.62}$, and $\mathrm{P}$ (S-OEMS$\mathrm{OEM})_{0.61}$ samples at a salt-doping ratio of $[\mathrm{EO}]:[\mathrm{Li}]=15: 1$. The temperature-dependent conductivity profiles of $\mathrm{LiCF}_{3} \mathrm{SO}_{3}$ doped tapered and non-tapered BPs are shown in Fig. 4(a). For comparison, the ionic conductivity of a $\mathrm{P}(\mathrm{S}-\mathrm{EO})$ sample with HEX morphology (Table 1 and ESI Fig. S4 $\uparrow$ ) at [EO]: [Li] = $15: 1$ also is shown in Fig. 4(a). The ionic conductivity of $\mathrm{P}(\mathrm{S}-\mathrm{EO})$ dropped substantially below $60{ }^{\circ} \mathrm{C}$ due to crystallization of PEO domain (see DSC data in ESI Fig. S5 $\dagger$ ). ${ }^{51}$ For the POEMcontaining specimens, all salt-doped polymers remained amorphous (ESI Fig. S5 $\dagger$ ) and showed the absence of a sharp drop in conductivity over the experimental temperature range. The conductivity of POEM-based BPs was $\sim 10^{-6} \mathrm{~S} \mathrm{~cm}^{-1}$ at 20 ${ }^{\circ} \mathrm{C}$, which was 2 orders of magnitude higher than $\mathrm{P}$ (S-EO) samples $\left(\sigma_{\mathrm{P}(\mathrm{S}-\mathrm{EO})} \sim 10^{-8} \mathrm{~S} \mathrm{~cm}^{-1}\right.$ at $\left.20{ }^{\circ} \mathrm{C}\right)$. Additionally, the POEM-based samples exhibited lower $T_{\mathrm{g}} \mathrm{s}$ (Fig. 4(b)) in comparison to $\mathrm{P}(\mathrm{S}-\mathrm{EO})$, suggesting the potential for enhanced segmental motion in POEM domains relative to PEO domains.

Among the three POEM-based BPs, the normal-tapered P(SSOEM-OEM $)_{0.62}$ showed the maximum ionic conductivity. Considering that all samples had the same morphology, we postulate that the improved ionic conductivity in the normaltapered sample resulted from the lower $T_{\mathrm{g}}$ of the conducting domains as reported in Fig. 4(b). ${ }^{52-55}$ As the POEM-based polymer electrolytes had similar molecular masses and chemical compositions, the shifting of the $T_{g}$ in the P(S-OEM) systems likely was caused by the presence of tapered interfaces. 

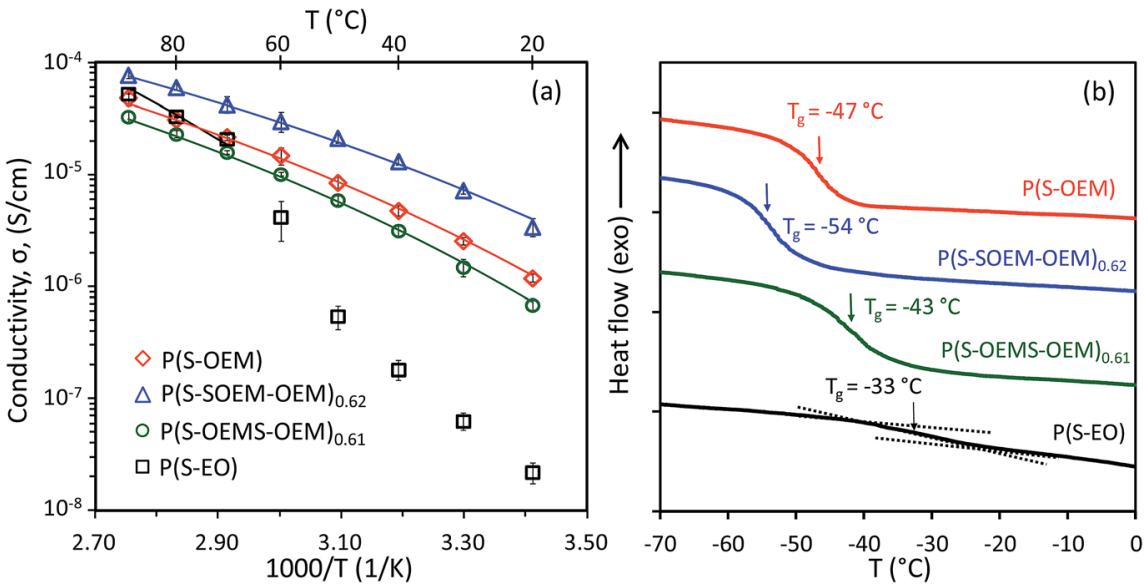

Fig. 4 (a) lonic conductivity profiles for $\mathrm{LiCF}_{3} \mathrm{SO}_{3}$-doped $\mathrm{P}(\mathrm{S}-\mathrm{OEM}), \mathrm{P}(\mathrm{S}-\mathrm{SOEM}-\mathrm{OEM})_{0.62}, \mathrm{P}(\mathrm{S}-\mathrm{OEMS}-\mathrm{OEM})_{0.61}$, and P(S-EO) at [EO] : [Li] $=15$ : 1. The reported values are averages from three samples with standard deviations indicated by error bars on the data points. The solid lines are $\mathrm{VFT}$ fits to the conductivity data. (b) Third-heating DSC traces of $\mathrm{LiCF}_{3} \mathrm{SO}_{3}$-doped $\mathrm{P}(\mathrm{S}-\mathrm{OEM}), \mathrm{P}(\mathrm{S}-\mathrm{SOEM}-\mathrm{OEM})_{0.62}, \mathrm{P}(\mathrm{S}-\mathrm{OEMS}-\mathrm{OEM})_{0.61}$, and $\mathrm{P}(\mathrm{S}$-EO)

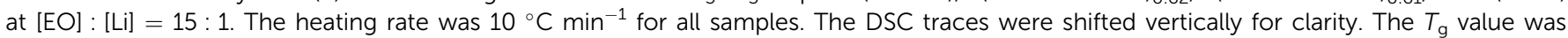
determined from the midpoint of the inflection in the third heating trace.

Additionally, we hypothesize that the direction of $T_{\mathrm{g}}$ shifting is influenced by the chain conformation at the block interface, which is different between the normal-tapered and inversetapered polymers. ${ }^{37,56}$

To examine the effect of $T_{\mathrm{g}}$ on the ion transport, the conductivity data for all $\mathrm{LiCF}_{3} \mathrm{SO}_{3}$-doped polymers were normalized by $T_{\mathrm{g}}$ as shown in Fig. 5 . The $T_{\mathrm{g}}$-scaled conductivity profiles of POEM-based polymers collapsed onto a single master curve, confirming that $T_{\mathrm{g}}$ plays a critical role for lithium-ion conduction in this BP system.

To further explore the influence of tapered interfaces on the ionic conductivity, the nonlinear Vogel-Fulcher-Tammann (VFT) equation (eqn (1)) was employed, ${ }^{1,57,58}$

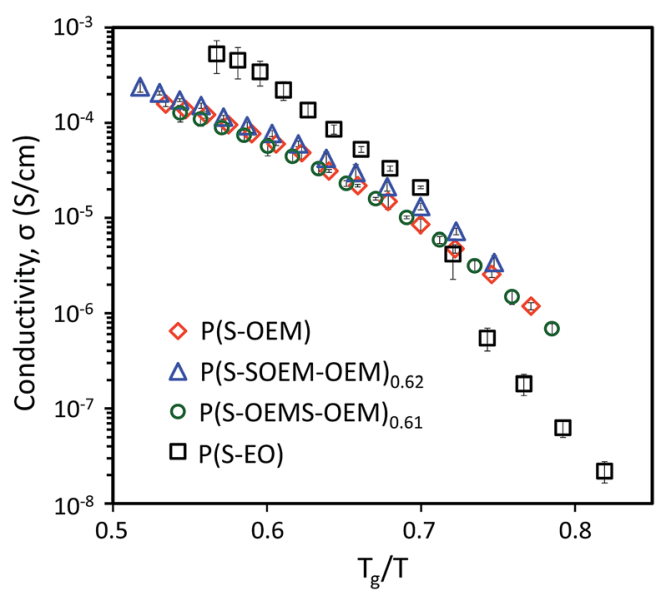

Fig. 5 Normalized ionic conductivity profiles for $\mathrm{LiCF}_{3} \mathrm{SO}_{3}$-doped $\mathrm{P}\left(\mathrm{S}\right.$-OEM), $\mathrm{P}\left(\mathrm{S}\right.$-SOEM-OEM) ${ }_{0.62}, \mathrm{P}(\mathrm{S} \text {-OEMS-OEM })_{0.61}$, and $\mathrm{P}(\mathrm{S}-\mathrm{EO})$ at [EO] : [Li] $=15: 1$. The scaled conductivity profiles of POEM-based polymers fell onto a single master curve. The deviation between the $\mathrm{P}(\mathrm{S}-\mathrm{EO})$ profile and the master curve likely was due to larger molar mass of $\mathrm{PEO}$ in $\mathrm{P}(\mathrm{S}-\mathrm{EO})$ and $\mathrm{PEO}$ crystallization at lower temperatures.

$$
\sigma=\sigma_{0} \mathrm{e}^{\frac{-B}{T-T_{0}}}
$$

in which $\sigma_{0}$ is the pre-exponential factor proportional to the number of charge carriers, $B$ is related to the activation energy of ion motion, $T$ is the temperature, and $T_{0}$ is the reference temperature. Herein, $T_{0}=T_{\mathrm{g}}-50 \mathrm{~K}$ was chosen, for which $T_{\mathrm{g}}$ is the glass transition temperature of the conducting domains in salt-doped polymers. ${ }^{59,60}$ The VFT equation (eqn (1)) was fit to the conductivity data in Fig. 4(a) as solid lines, and the corresponding $B$ parameters are reported in Table 2 . The lower $B$ values in the POEM systems relative to the $\mathrm{P}(\mathrm{S}-\mathrm{EO})$ material were expected due to the high chain mobility of the short PEO side chains compared to the long PEO backbone. ${ }^{61}$ The $\mathrm{P}(\mathrm{S}-$ SOEM-OEM) $)_{0.62}$ exhibited the lowest VFT activation energy among POEM-based BPs. Although the reduction of $B$ values was slight, the combination of improved ionic conductivity and low $T_{\mathrm{g}}$ as detailed above demonstrate that the normal-tapered BP electrolytes provided superior transport properties relative to their inverse-tapered and non-tapered counterparts.

We further investigated the effect of taper fraction, $f_{\text {taper }}$, on TBP ionic conductivity using normal-tapered BPs with $f_{\text {taper }}=$

Table 2 VFT fitting parameters for $\mathrm{LiCF}_{3} \mathrm{SO}_{3}$-doped polymers

\begin{tabular}{lllr}
\hline Polymer & {$[\mathrm{EO}]:[\mathrm{Li}]$} & $T_{\mathrm{g}}\left({ }^{\circ} \mathrm{C}\right)^{a}$ & \multicolumn{1}{c}{$B(\mathrm{~K})^{b}$} \\
\hline $\mathrm{P}($ S-OEM $)$ & $15: 1$ & -47 & $1149 \pm 27$ \\
$\mathrm{P}(\text { S-SOEM-OEM) })_{0.62}$ & $15: 1$ & -54 & $1057 \pm 33$ \\
$\mathrm{P}(\text { S-OEMS-OEM) })_{0.61}$ & $15: 1$ & -43 & $1154 \pm 55$ \\
$\mathrm{P}($ S-EO $)$ & $15: 1$ & -33 & $1523^{c} \pm 82$ \\
P(S-SOEM-OEM) $)_{0.62}$ & $24: 1$ & -61 & $933 \pm 32$ \\
$\mathrm{P}(\text { S-SOEM-OEM })_{0.32}$ & $24: 1$ & -51 & $1031 \pm 53$
\end{tabular}

${ }^{a} T_{\mathrm{g}}$ of the conducting domains (POEM : $\mathrm{LiCF}_{3} \mathrm{SO}_{3}$ and PEO : $\mathrm{LiCF}_{3} \mathrm{SO}_{3}$ ). ${ }^{b}$ The standard deviation was determined from measurements of three different samples. ${ }^{c}$ Data fit was over a temperature range of $70{ }^{\circ} \mathrm{C}$ to $150{ }^{\circ} \mathrm{C}$. 
$0.62\left(\mathrm{P}(\mathrm{S}-\mathrm{SOEM}-\mathrm{OEM})_{0.62}\right)$ and $f_{\text {taper }}=0.32$ (P(S-SOEM$\left.\mathrm{OEM})_{0.32}\right)$. The SAXS profile for $\mathrm{LiCF}_{3} \mathrm{SO}_{3}$-doped P(S-SOEMOEM $)_{0.32}$ exhibited a LAM phase at a salt-doping ratio of [EO] : $[\mathrm{Li}]=15: 1$ (ESI Fig. S6†). To eliminate the morphology effect on the ionic conductivity $\left(\mathrm{P}(\mathrm{S}-\mathrm{SOEM}-\mathrm{OEM})_{0.62}\right.$ exhibited a HEX morphology at $15: 1$ ), a salt-doping ratio of $24: 1$ was chosen to compare these TBPs. Both polymers exhibit the same morphology at this ratio as demonstrated below. The SAXS patterns for $\mathrm{LiCF}_{3} \mathrm{SO}_{3}$-doped $\mathrm{P}(\mathrm{S} \text {-SOEM-OEM })_{0.62}$ and $\mathrm{LiCF}_{3} \mathrm{SO}_{3}$ doped $\mathrm{P}(\mathrm{S}-\mathrm{SOEM}-\mathrm{OEM})_{0.32}$ are displayed in Fig. 6(a). P(S-SOEMOEM $)_{0.62}$ showed SAXS diffraction peaks located at $q / q^{*}=1$ and 2 . These peak ratios corresponded to a LAM morphology, which was supported by the TEM micrograph in Fig. 6(b). The P(SSOEM-OEM) $)_{0.32}$ sample, which had a smaller taper fraction, also exhibited a LAM morphology as evidenced by the SAXS peak ratios of 1, 2, and 3 shown in Fig. 6(a) and the corresponding TEM micrograph in Fig. 6(c). From the primary peak locations, the domain spacings of $\mathrm{LiCF}_{3} \mathrm{SO}_{3}$-doped P(S-SOEM$\mathrm{OEM})_{0.62}$ and $\mathrm{LiCF}_{3} \mathrm{SO}_{3}$-doped $\mathrm{P}(\mathrm{S} \text {-SOEM-OEM })_{0.32}$ were 19.1 $\mathrm{nm}$ and $22.5 \mathrm{~nm}$, respectively. This difference likely did not occur as a result of molecular mass or composition, which were similar between the two samples. Instead, the smaller domain spacing in $\mathrm{P}(\mathrm{S}-\mathrm{SOEM}-\mathrm{OEM})_{0.62}$ was attributed to the wider tapered interface and reduced chain stretching that resulted from the increased compatibility between the two blocks. ${ }^{35,37}$

Fig. 7(a) shows the temperature-dependent ionic conductivity profiles for $\mathrm{P}(\mathrm{S}-\mathrm{SOEM}-\mathrm{OEM})_{0.62}$ and $\mathrm{P}(\mathrm{S}-\mathrm{SOEM}-\mathrm{OEM})_{0.32}$ at a salt-doping ratio of $24: 1$. P(S-SOEM-OEM $)_{0.32}$ exhibited lower conductivities relative to $\mathrm{P}(\mathrm{S}-\mathrm{SOEM}-\mathrm{OEM})_{0.62}$ over the entire experimental temperature range, which was expected when considering that the $T_{\mathrm{g}}$ of $\mathrm{P}(\mathrm{S} \text {-SOEM-OEM })_{0.32}$ was $10^{\circ} \mathrm{C}$ higher than that of $\mathrm{P}(\mathrm{S}-\mathrm{SOEM}-\mathrm{OEM})_{0.62}$ (Table 2). Normalization of the data to $T_{\mathrm{g}} / T$ collapsed the ionic conductivities for the two $\mathrm{LiCF}_{3} \mathrm{SO}_{3}$-doped normal-tapered materials onto a single curve (Fig. 7(b)), again suggesting that ion transport in these

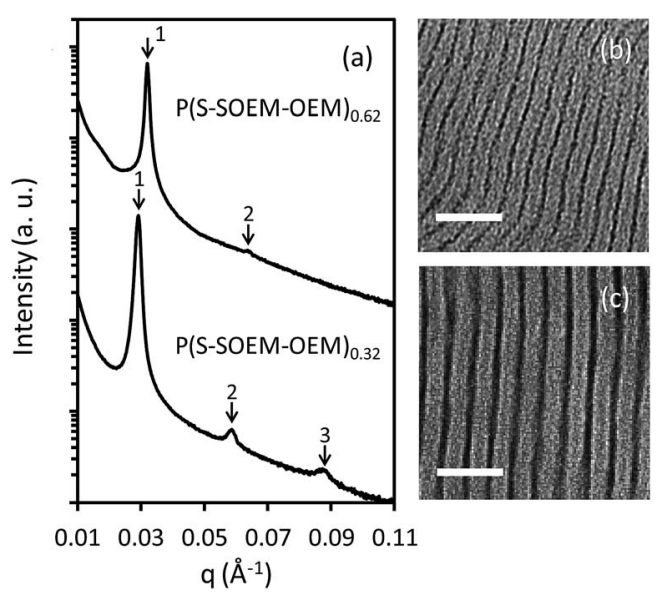

Fig. 6 (a) SAXS data for $\mathrm{LiCF}_{3} \mathrm{SO}_{3}$-doped P(S-SOEM-OEM) 0.62 and $\mathrm{LiCF}_{3} \mathrm{SO}_{3}$-doped P(S-SOEM-OEM) 0.32 at [EO] : [Li] = $24: 1$. Data were shifted vertically for clarity. TEM micrographs of (b) $\mathrm{LiCF}_{3} \mathrm{SO}_{3}$-doped $\mathrm{P}(\mathrm{S}-\mathrm{SOEM}-\mathrm{OEM})_{0.62}$ and (c) $\mathrm{LiCF}_{3} \mathrm{SO}_{3}$-doped $\mathrm{P}\left(\mathrm{S}\right.$-SOEM-OEM) 0.32 $_{0 .}$. TEM samples were stained with $\mathrm{RuO}_{4}$ vapor to darken the POEM domains. Scale bars represent $50 \mathrm{~nm}$.
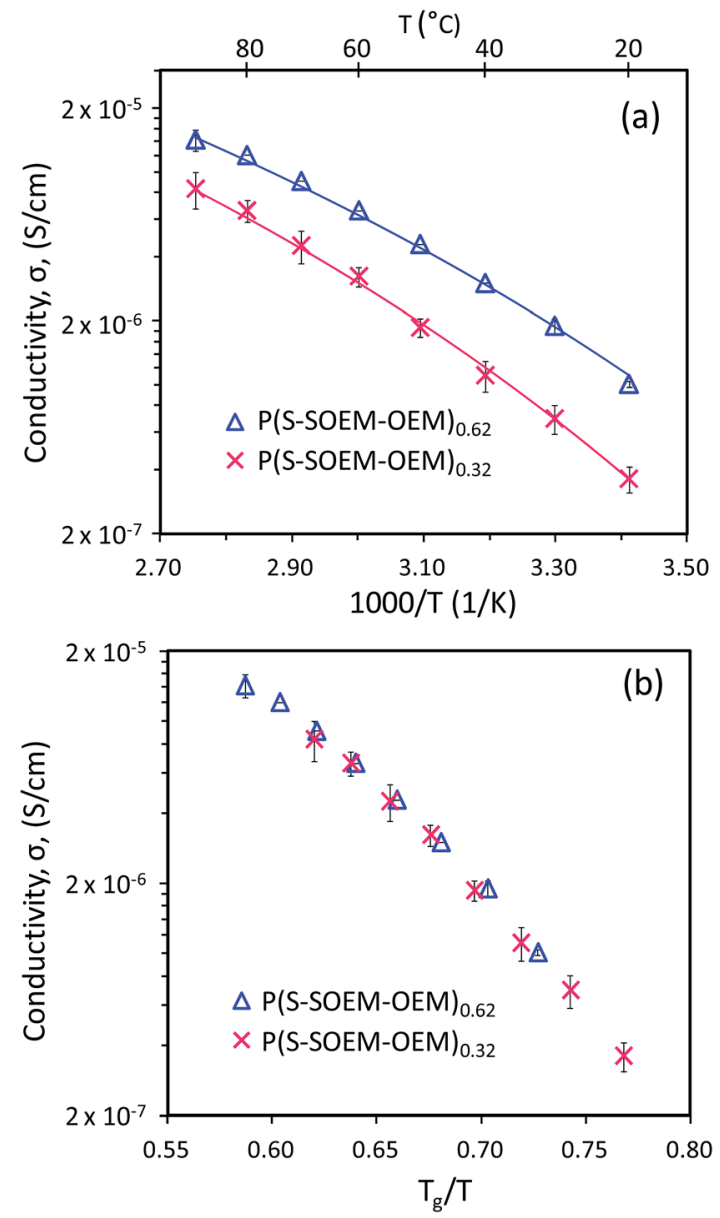

Fig. 7 (a) Temperature-dependent conductivity profiles and (b) normalized ionic conductivity profiles for $\mathrm{LiCF}_{3} \mathrm{SO}_{3}$-doped $\mathrm{P}(\mathrm{S}$-SOEM$\mathrm{OEM})_{0.62}$ and $\mathrm{LiCF}_{3} \mathrm{SO}_{3}$-doped P(S-SOEM-OEM) 0.32 at $[\mathrm{EO}]:[\mathrm{Li}]=$ $24: 1$. The reported values of ionic conductivity are averages from three samples with standard deviations indicated by error bars on the data points. The solid lines in (a) are VFT fits.

materials is dominated by the $T_{\mathrm{g}}$. Moreover, this result showed that the $T_{\mathrm{g}}$ could be tuned by the interfacial width, thus allowing control of the ionic conductivity. Analysis of the ionic conductivity using the VFT equation also revealed that the VFT activation energy decreased when the tapered interface was increased (Table 2). This result possibly indicates that the modification of interfacial structure between blocks can reduce the barriers for ion motion and promote ion transport. In future work, a systematic analysis of TBP mechanical properties is useful to gain insight into the additional effects of tapering. As $T_{\text {ODT }}$ and $T_{\mathrm{g}}$ of the salt-doped BPs have shown a strong dependence on the interfacial profile between polymer blocks, an impact in mechanical properties by tapered interfaces may be expected.

\section{Conclusions}

We prepared, for the first time, TBP electrolytes based on $\mathrm{P}(\mathrm{S}$ OEM) BPs. This new family of nanostructured polymer electrolytes provided a unique approach for tuning thermal and 
transport properties at constant molecular mass and chemical composition. Of particular importance, the tapered interfaces presented an excellent ability to manipulate $T_{\mathrm{g}}$ of BP electrolytes through adjustments in the taper profile and taper volume fraction, thus enabling the ability to design materials with tailored conductivity. This interfacial modification approach for polymer electrolytes offers an avenue for solving the dueling problems of efficiency and cost in current electrolytes and displays promising potential for energy storage devices.

\section{Acknowledgements}

We gratefully acknowledge AFOSR-PECASE (FA9550-09-1-0706) for financial support. R. Remy is supported by NIST (70NANO$\mathrm{BIOH} 256)$ and funding provided through the Department of Materials Science and Engineering at UD. This research used resources of the Advanced Photon Source, a U.S. Department of Energy (DOE) Office of Science User Facility operated for the DOE Office of Science by Argonne National Laboratory under Contract no. DE-AC02-06CH11357. We thank the W. M. Keck Electron Microscopy Facility at UD for use of the TEM and cryomicrotome facilities. We also acknowledge the Advanced Materials Characterization Laboratory at UD for the use of DSC and SAXS instruments.

\section{Notes and references}

1 R. C. Agrawal and G. P. Pandey, J. Phys. D: Appl. Phys., 2008, 41, 223001.

2 J.-M. Tarascon and M. Armand, Nature, 2001, 414, 359-367.

3 K. Xu, Chem. Rev., 2014, 114, 11503-11618.

4 D. T. Hallinan and N. P. Balsara, Annu. Rev. Mater. Res., 2013, 43, 503-525.

5 J. B. Goodenough and K.-S. Park, J. Am. Chem. Soc., 2013, 135, 1167-1176.

6 I. Y. Choi, H. Kim and M. J. Park, RSC Adv., 2014, 4, 6133361336.

7 K. Xu, Chem. Rev., 2004, 104, 4303-4418.

8 K. J. Harry, D. T. Hallinan, D. Y. Parkinson, A. A. MacDowell and N. P. Balsara, Nat. Mater., 2014, 13, 69-73.

9 W. Li, H. Zheng, G. Chu, F. Luo, J. Zheng, D. Xiao, X. Li, L. Gu, H. Li, X. Wei, Q. Chen and L. Chen, Faraday Discuss., 2014, DOI: 10.1039/c4fd00124a.

10 M. Jacoby, Chemical \& Engineering News Archive, 2013, 91, 3337.

11 E. Quartarone and P. Mustarelli, Chem. Soc. Rev., 2011, 40, 2525-2540.

12 R. Senthil Kumar, M. Raja, M. Anbu Kulandainathan and A. Manuel Stephan, RSC Adv., 2014, 4, 26171-26175.

13 Y. Lin, J. Li, Y. Lai, C. Yuan, Y. Cheng and J. Liu, RSC Adv., 2013, 3, 10722-10730.

14 W.-S. Young, W.-F. Kuan and T. H. Epps, III, J. Polym. Sci., Part B: Polym. Phys., 2014, 52, 1-16.

15 P. W. Majewski, M. Gopinadhan and C. O. Osuji, Soft Matter, 2013, 9, 7106-7116.

16 W.-S. Young and T. H. Epps, III, Macromolecules, 2012, 45, 4689-4697.
17 B. K. Cho, A. Jain, S. M. Gruner and U. Wiesner, Science, 2004, 305, 1598-1601.

18 R. L. Weber, Y. S. Ye, A. L. Schmitt, S. M. Banik, Y. A. Elabd and M. K. Mahanthappa, Macromolecules, 2011, 44, 57275735.

19 I. Nakamura and Z.-G. Wang, ACS Macro Lett., 2014, 3, 708711.

20 Y. Ye, S. Sharick, E. M. Davis, K. I. Winey and Y. A. Elabd, ACS Macro Lett., 2013, 2, 575-580.

21 M. Singh, O. Odusanya, G. M. Wilmes, H. B. Eitouni, E. D. Gomez, A. J. Patel, V. L. Chen, M. J. Park, P. Fragouli, H. Iatrou, N. Hadjichristidis, D. Cookson and N. P. Balsara, Macromolecules, 2007, 40, 4578-4585.

22 M. W. Schulze, L. D. McIntosh, M. A. Hillmyer and T. P. Lodge, Nano Lett., 2013, 14, 122-126.

23 C. Wang, T. Sakai, O. Watanabe, K. Hirahara and T. Nakanishi, J. Electrochem. Soc., 2003, 150, A1166-A1170.

24 A.-V. G. Ruzette, P. P. Soo, D. R. Sadoway and A. M. Mayes, J. Electrochem. Soc., 2001, 148, A537-A543.

25 W.-F. Kuan, R. Roy, L. Rong, B. S. Hsiao and T. H. Epps, III, ACS Macro Lett., 2012, 1, 519-523.

26 R. Roy, J. K. Park, W.-S. Young, S. E. Mastroianni, M. S. Tureau and T. H. Epps, III, Macromolecules, 2011, 44, 3910-3915.

27 P. Hodrokoukes, G. A. Floudas, S. Pispas and N. Hadjichristidis, Macromolecules, 2001, 34, 650-657.

28 T. Hashimoto, Y. Tsukahara, K. Tachi and H. Kawai, Macromolecules, 1983, 16, 648-657.

29 T. Hashimoto, Y. Tsukahara and H. Kawai, Polym. J., 1983, 15, 699-711.

30 R. Jiang, Q. Jin, B. Li, D. Ding, R. A. Wickham and A.-C. Shi, Macromolecules, 2008, 41, 5457-5465.

31 M. M. Mok, S. Pujari, W. R. Burghardt, C. M. Dettmer, S. T. Nguyen, C. J. Ellison and J. M. Torkelson, Macromolecules, 2008, 41, 5818-5829.

32 M. D. Lefebvre, M. Olvera de la Cruz and K. R. Shull, Macromolecules, 2004, 37, 1118-1123.

33 K. R. Shull, Macromolecules, 2002, 35, 8631-8639.

34 K. Matyjaszewski and J. H. Xia, Chem. Rev., 2001, 101, 29212990.

35 T. Pakula and K. Matyjaszewski, Macromol. Theory Simul., 1996, 5, 987-1006.

36 N. Singh, M. S. Tureau and T. H. Epps, III, Soft Matter, 2009, 5, 4757-4762.

37 J. R. Brown, S. W. Sides and L. M. Hall, ACS Macro Lett., 2013, 2, 1105-1109.

38 B. S. Beckingham and R. A. Register, Macromolecules, 2011, 44, 4313-4319.

39 M. M. Mok, J. Kim and J. M. Torkelson, J. Polym. Sci., Part B: Polym. Phys., 2008, 46, 48-58.

40 M. M. Mok, J. Kim, C. L. H. Wong, S. R. Marrou, D. J. Woo, C. M. Dettmer, S. T. Nguyen, C. J. Ellison, K. R. Shull and J. M. Torkelson, Macromolecules, 2009, 42, 7863-7876.

41 T. A. Huy, L. H. Hai, R. Adhikari, R. Weidisch, G. H. Michler and K. Knoll, Polymer, 2003, 44, 1237-1245. 
42 S. Jouenne, J. A. González-León, A.-V. Ruzette, P. Lodefier, S. Tencé-Girault and L. Leibler, Macromolecules, 2007, 40, 2432-2442.

43 J. Rolland, J. Brassinne, J. P. Bourgeois, E. Poggi, A. Vlad and J. F. Gohy, J. Mater. Chem. A, 2014, 2, 11839-11846.

44 J.-H. Helen Wang and R. H. Colby, Soft Matter, 2013, 9, 10275-10286.

45 X. Jiang, G. Zhang, R. Narain and S. Liu, Soft Matter, 2009, 5, 1530-1538.

46 F. R. Mayo and F. M. Lewis, J. Am. Chem. Soc., 1944, 66, 15941601.

47 J. Brandrup, E. H. Immergut and E. A. Grulke, in Polymer Handbook, Wiley, New York, 4th edn, 1999.

48 D. W. Van Krevelen and K. Te Nijenhuis, in Properties of Polymers, ed. D. W. V. Krevelen and K. T. Nijenhuis, Elsevier, Amsterdam, 4th edn, 2009, pp. 71-108.

49 W.-S. Young and T. H. Epps, III, Macromolecules, 2009, 42, 2672-2678.

50 W.-S. Young, J. N. L. Albert, A. B. Schantz and T. H. Epps, III, Macromolecules, 2011, 44, 8116-8123.

51 C. D. Robitaille and D. Fauteux, J. Electrochem. Soc., 1986, 133, 315-325.
52 S. Liang, M. V. O'Reilly, U. H. Choi, H.-S. Shiau, J. Bartels, Q. Chen, J. Runt, K. I. Winey and R. H. Colby, Macromolecules, 2014, 47, 4428-4437.

53 R. Khurana, J. L. Schaefer, L. A. Archer and G. W. Coates, J. Am. Chem. Soc., 2014, 136, 7395-7402.

54 M. D. Green, D. Wang, S. T. Hemp, J.-H. Choi, K. I. Winey, J. R. Heflin and T. E. Long, Polymer, 2012, 53, 3677-3686.

55 Y. Zhang, C. A. Lim, W. Cai, R. Rohan, G. Xu, Y. Sun and H. Cheng, RSC Adv., 2014, 4, 43857-43864.

56 P. Hodrokoukes, S. Pispas and N. Hadjichristidis, Macromolecules, 2002, 35, 834-840.

57 K. P. Barteau, M. Wolffs, N. A. Lynd, G. H. Fredrickson, E. J. Kramer and C. J. Hawker, Macromolecules, 2013, 46, 8988-8994.

58 L. D. McIntosh, T. Kubo and T. P. Lodge, Macromolecules, 2014, 47, 1090-1098.

59 O. Kim, S. Y. Kim, H. Ahn, C. W. Kim, Y. M. Rhee and M. J. Park, Macromolecules, 2012, 45, 8702-8713.

60 R. Yuan, A. A. Teran, I. Gurevitch, S. A. Mullin, N. S. Wanakule and N. P. Balsara, Macromolecules, 2013, 46, 914-921.

61 J. Karo and D. Brandell, Solid State Ionics, 2009, 180, 12721284. 